\title{
Reflections: Tributes to Duane M. Rumbaugh (1929-2017)
}

\author{
"Every year on my birthday, there are fireworks and parades in the streets."
}

Duane M. Rumbaugh was born on the $4^{\text {th }}$ of July, 1929, in the tiny rural town of Maynard, Iowa. The youngest of three children born to the Reverend and Ida (Traudt) Rumbaugh, Duane was raised during the Great Depression, the Dust Bowl, a world at war, and the hard work that comes from working on neighboring farms. Too young for World War II and too academically oriented to remain on the farm, Rumbaugh enrolled in 1946 at the University of Dubuque to study psychology. He would earn his degree there four years later, despite spending his entire senior year taking classes at the University of Iowa. His opportunities to learn from outstanding faculty in Iowa City inspired Rumbaugh to pursue graduate study in experimental psychology. His 1951 master's research was supervised by Professor Charles Perkins at Kent State University in Ohio, and his subsequent doctoral research was under the direction of Professor Maurice Smith at the University of Colorado. Smith and Perkins were both students of Professor Kenneth Spence at Iowa, and thus, Rumbaugh was thoroughly trained in the Hull-Spence tradition and framework. His 1955 dissertation was titled An Investigation of the Relationship between Drive Intensity and the Growth of Habit Strength.

Dr. Rumbaugh's first postdoctoral position was a one-year teaching opportunity at San Diego State College, which, because of his excellent work, would ultimately last 15 years. He earned tenure and promotion through the ranks, teaching comparative psychology and conducting research with a variety of animals at the San Diego Zoo. His publications during this period, and particularly his Harlow-inspired work with nonhuman primates on discrimination learning and reversal, earned Rumbaugh a call from Geoffrey Bourne, Director of the Yerkes Regional Primate Research Center in Atlanta. Bourne offered Rumbaugh the position of Associate Director and Chief of Primate Behavior, and, in 1969, Rumbaugh moved his research program to Atlanta and Yerkes. Two years later, he accepted appointment as professor and chair of psychology at Georgia State University. Professor Rumbaugh served as department chair for 18 years, and retired from Georgia State in 2001 as Regents Professor of Psychology and Biology.

Dr. Rumbaugh's long and distinguished career yielded more than 125 published articles and chapters on a wide range of topics within comparative psychology. He authored two books: The Intelligence of Apes and Other Rational Beings (2003, with David Washburn) and With Apes in Mind (2013). He edited or coedited many other books, most notably Language Learning by a Chimpanzee: The LANA Project (1977). Across the years, these publications attest to his shift from the Hull-Spence framework to a comparativecognition perspective that he termed rational behaviorism - a methodologically behaviorist view that embraced operant and classical conditioning while allowing for emergent forms of learning that are relational rather than associative, produced when an animal perceives salient regularities in experience. Examples of emergent learning phenomena studied by Rumbaugh include positive transfer of learning in the Transfer Index measure of intelligence, counting and other aspects of numerical cognition by monkeys and apes, and language and communication by symbol-competent chimpanzees. It was this latter work, the training of chimpanzee Lana and other apes to use a computer-based keyboard and visuographic symbols called lexigrams to communicate, for which Duane Rumbaugh is best known.

In support of ape-language research - and translational application of this research in intervention work with nonspeaking children with developmental disabilities-Rumbaugh founded the Georgia State 
University Language Research Center (LRC) in 1981, and served as its Director until his retirement in 2001. At the LRC, Rumbaugh also pioneered the use of computer-game technology in studies of primate cognition. The computerized test system that he developed for research with monkeys has become a standard testing paradigm in comparative cognition.

Dr. Rumbaugh attracted grant support for these and many other contributions to comparative psychology from various sources, including more than three decades of continuous grant support from the National Institute for Child Health and Human Development. His contributions to the field were recognized with countless honors, including the Donald O. Hebb Distinguished Scientific Contributions Award (2005, American Psychological Association Division 6) and the Lifetime Achievement Award (2016, Society for Experimental Psychology and Cognitive Science). Each year, Georgia State University awards the Duane M. Rumbaugh Fellowship to an outstanding doctoral student or postdoc engaged in noninvasive behavioral research on emergent behaviors in nonhuman primates.

Duane Rumbaugh died peacefully on June 23, 2017, following a stroke. In the years leading up to his death, Dr. Rumbaugh remained intellectually engaged and active in research from his home in Highland Park, NJ, where he lived near his daughter, son-in-law, and grandsons.

The following comments come from just a small portion of those who Duane affected so positively as a mentor, colleague, and friend throughout his long career and his amazing life.

I ended up at the Language Research Center and Georgia State University by lucky accident. I did my undergraduate work at Oglethorpe University in Atlanta, majoring in just about everything before realizing psychology was for me. But, by then, I was not sure what area to concentrate on for graduate school. Although I applied to some places, none seemed to fit, and I decided to take a year off after graduation. For the first time, I began reading academic books that I wanted to read, rather than those I needed to read for my classes, and I was drawn to work on ape language and ape cognition. I came across the work of Duane Rumbaugh and Sue Savage-Rumbaugh, and realized they were right down the road from me! This was late in the spring semester of my senior year. I looked up information about applying to the grad program, to prepare for the next year, and then realized Georgia State University was on a quarter system. What luck! I could still apply in late spring for the following fall. So I did, and when Duane called me to invite me to interview, I could not believe it. I met Sherman, Austin, Panzee, Kanzi, and the other apes that day, as well as Duane, Sue, and David Washburn (who, as I recall, tried to "chase" me away from the program, but that is another story). I guess the interview went well, though, because I got into the program, and had the chance to be one of Duane's last students.

I am so very grateful to Duane for his unwavering support of my career, and his constant willingness to let me try new things. I began working on numerical cognition with the chimpanzees and monkeys, but he pushed me to choose a unique topic for my master's thesis, and that is how I became interested in selfcontrol and delay of gratification. Duane also encouraged me to remember that comparative psychology included working with humans, and so I tried to find opportunities to work with adults and children as well. And, Duane always reminded me to worry less about where things were published, and more about trying to really answer a question, and really understand what animals do. He often noted that he was most proud of some of his book chapters, because in those he had the freedom to engage the reader with details and ideas that could not always make it into journal articles.

Duane was a great mentor, but he also was a constant presence at the Language Research Center. He took a keen interest in everyone who worked there. Many at the LRC knew of his fondness for the Piccadilly Cafeteria down the street, and although the food may not have been the greatest, Duane always said that an important rule to remember in graduate school was to never pass up free food, and 
whenever possible, eat somewhere that lets you get truly full since it might be a while before you ate again! Duane's birthday was the $4^{\text {th }}$ of July, and it always impressed me that, rather than being celebrated himself, he liked to instead come to the lab on that day (when we were short-staffed and grad students often were taking care of the animals). He always arrived with cake and ice cream for all of us, and for all of his apes, who he made sure to visit. As in so many other ways, even though his birthday should have been focused on him, he instead made sure that others were made to feel good.

There was a time early in my graduate studies when I needed to leave Georgia and school to handle some difficult family matters. I knew I would be gone a long time, and I honestly did not know if I would be able to return. I met with Duane, to tell him that perhaps it would be best if I suspended my graduate training, because I would not be able to support the lab, or contribute much to the science. Without hesitation (and before I had even finished explaining), Duane told me that he would not have that - he asked if I would still be able to find some time to write, and when I told him I thought I could, he told me he would make sure to find things I could do from a distance, and that when I was ready I could come back and pick right back up where I left. Without that trust on his part, my career likely would have ended that summer. For that, I am forever grateful.

Duane taught me how to enjoy and appreciate science, and to try to promote the interests of students as much as anything else. I have tried to be the same kind of mentor and colleague to my students and collaborators that Duane was for so many of us. If I could do even half as well as he did, I would be truly satisfied with my effort.

Michael Beran

Comparative Psychology has lost one of its greatest ambassadors with the passing of Duane M. Rumbaugh in June 2017. Always a little ahead of his time, Duane's prolific scientific contributions pushed the field forward and maintained relevance over the span of decades. In addressing the evolution of animal learning from a behaviorist perspective, he nevertheless investigated primate cognition before the Cognitive Revolution and when few scientists were thinking about animal thought. His ideas about language and other emergent behaviors in apes and monkeys have nestled nicely into a Dynamic Systems framework of self-organizing behavioral systems.

After making significant contributions to our understanding of nonhuman primates' capacity for complex learning, most famously in partnership with the chimpanzee, Lana, Duane served for many years as the founding Director of the Language Research Center (LRC). The success of the research at the LRC over more than thirty-five years has been in large part due to his efforts as Director to secure funding, hire outstanding staff, and navigate administrative waters to provide the environment to keep the apes and monkeys under his charge safe and thriving both physically and psychologically. Knowing how important early rearing and environmental stimulation are to all primates, Duane envisioned and then created an environment -- with his colleague and wife Sue Savage-Rumbaugh -- where, although captive, the LRC primates were (and are still) intellectually challenged and socially engaged. The care and spirit that the Rumbaughs instilled is still a tangible force guiding the LRC's work today under its second and current Director, David Washburn.

During the years that I knew him at the LRC and long before he was truly elder, Duane was an 'Elder Statesman' in the field of primate cognition -- a humble scholar yet so accomplished and confident in his own contributions to science that he could focus on supporting the achievements of others. Although he was not my graduate advisor (Sue took on that role for me), he was certainly one of my mentors, providing opportunities for me to build my academic chops and, as my department Chair at Georgia State University, pushing me when I needed that last nudge to finish my dissertation. He encouraged all of his 
students and associates to pursue their ideas with rigor and vigor, embracing yet managing the risks that inherently accompany research that requires close contact and long-term relationships between humans and members of other primate species.

Although the LRC has faced many challenges large and small over the years, the research that has arisen from its work has been unique in shedding light on higher-order cognitive skills in apes and monkeys. The scope of knowledge shared by the scientists (too many to list but they know who they are) who either began their careers as students under Duane's guidance or were welcomed to the LRC as collaborators is, frankly, mind-boggling - encompassing language, memory, numeracy, spatial cognition, classification, executive function, tool use, and other skills in a range of ape and monkey species raised in a variety of environments. Without Duane's efforts and support of others, we would not know nearly as much about the minds of nonhuman primates as we do. Nor, I believe, would we have seen so clearly how culturallyrich early rearing and the plasticity of the primate brain can so powerfully combine to bolster or even change how individuals of other species - as well as our own - cognitively process and navigate their world. Indeed, one of his most far-reaching contributions was to include research using Lana's lexigram system with children and youth who had been profoundly challenged by trying to communicate through language or other symbol systems in the LRC's mission. This work, conducted by Duane's colleagues Mary Ann Romski and Rose Sevcik with several collaborators, has been enormously successful in giving children voice and agency through lexigram-based communication, and his role in facilitating the early years of this project was, I believe, a particular source of gratification for Duane.

As I write this, I can picture Duane in his many roles as a scholar and administrator. My fondest memories of Duane, however, are of the times we spent together with our young ape friends. Duane always spoke to the chimpanzees and bonobos with a gentle and deep respect; these were his partners in discovery and he never took their contributions or cooperation for granted. Soon after I joined the lab as a graduate student, bonobo Panbanisha and chimpanzee Panzee were born, and I had the unbelievably good fortune to be assigned to their co-rearing team. It still brings a smile to me these many years later, as I remember him, a widely known and respected scientist, playing 'chase' or sharing a surprise treat with 'the girls' as we visited with him around the lab.

Duane M. Rumbaugh leaves an incredible legacy through both his research and the contributions of those who followed him. Although my own primary research focus is no longer on nonhuman primates, but human ones, the perspective I gained at the LRC stays with me to this day. This perspective influences how I view human skill, cognition, and indeed our species' niche in space and time. I am ever grateful to Duane and the LRC for giving me this privilege. I've no doubt that future generations will continue to appreciate and benefit from Duane's many contributions to understanding primate minds.

\section{Karen Brakke}

Years after my first interaction with Duane, I realized that he truly set the tone of my graduate careerperhaps without ever knowing it himself. I arrived at the LRC just weeks after graduating from Franklin \& Marshall College with my undergraduate degree in Animal Behavior. I was about to embark on what became a long journey in the PhD program at Georgia State and was encouraged to arrive early the summer before our fall semester to get my footing at the lab. It was a fantastic opportunity to establish relationships with friends who would become mentors, mentors who would become friends and plenty of other synergistic iterations of the two. Duane, while serving as an intellectual mentor long before I met him, was not someone with whom I would have the pleasure of working with closely over the years. His impact on me took hold over one lunch meeting at the Piccadilly (if memory serves, it should stand to reason this was the place) days after my arrival at the lab. 
In my first few days at the lab, I remember happening across Duane around the faculty offices and being introduced as the new graduate student. I knew Duane's work well (as well as any fresh new graduate student could) and had admired his work along with many of his colleagues at the LRC for a few years at this point. Duane was excited about the release of his newly published book with David Washburn. "The Intelligence of Apes and Other Rational Beings" and handed me a signed copy which I would come to treasure over the years. He offered to have lunch with me the next day to "talk about the book." I of course accepted thinking some combination of "Wow, I get to have lunch with THE DUANE RUMBAUGH!" and "So now I have to read 400-some-odd pages in the next 24 hours?" I went back to my office and began to read. I did some quick searches of his publications to brush up on references until I was satisfied that I could sit down with Duane the next day and tell him about how great his work was. At lunch the next day, I nervously began to thank Duane for his company. I told him I enjoyed what I could finish of his book. Almost as if he was shy of his own work and accomplishments, he quickly changed the subject to me. Gulp. This pattern continued throughout lunch - every time I began to talk about his work, he would redirect and continue pushing me to discuss why I was at the LRC and what kinds of research I was interested in doing for me. He wasn't interested in discussing his accomplishments, but rather my ideas for projects inspired by my interests alone. I wish I could remember what nonsense I proposed as he pushed, but his message was not lost - innovate and strive for intellectual independence. Every time I referenced someone else's work and how it might inspire my own ideas, he gave it a respectful nod before dismissing his and other's work in favor of encouraging creativity and originality.

I don't believe I recognized or appreciated the tone of our lunch at the time for what it has meant to me for years. I will forever be grateful for the moment I realized that it was Duane, after many years, who inspired me not to think like him, but to think like me.

Tim Flemming

I will always remember Duane as a true friend and devoted mentor. He had an infectious laugh and was always ready with a joke or colorful story.

I first met Duane as an undergraduate student in his Comparative Psychology course. Throughout the entire semester he never referred to lecture notes, overheads or powerpoint slides. It was a truly impressive teaching performance; one that I still try to emulate today. His lecture style was conversational, delivered in his easy-going manner. However, these conversations often resulted in offthe-cuff discussions of dissertation-level research topics where Duane would challenge us to "shoot down" his idea; we rarely could.

As a graduate student in Duane's laboratory I benefitted daily from his intellect and passion for research. Later, as I began the search for my first academic appointment I benefitted from his guidance, expertise and friendship. Daily, I am reminded of the impact he has on me, my family and my students. Just yesterday, in my History and Systems of Psychology course, I regaled my students with stories I "borrowed" from Duane.

Over the years we grew further apart, for the usual reasons, but it was always comforting to know that he was still my friend. Years later, his was always the first email I would read each morning and seeing his name in my inbox would always bring a smile to my face.

Jonathan Gulledge 
Duane Rumbaugh had a major impact on my life even before I met him! Before deciding to attend college in my mid-forties for a B.A. in Anthropology, I was captivated by books about the cognitive abilities and behaviors of chimpanzees. Of course, several of the books I read (in particular, Kanzi: The Ape at the Brink of the Human Mind and Intelligence of Apes and Other Rational Beings) were about some of the fascinating research of Duane and others at the Language Research Center. I was amazed at the abilities of Lana, Sherman, Austin, Kanzi, and Panzee, and this prompted me to attend Stony Brook University where there were several primatologists. I never dreamed that one day I would continue on to a Cognitive Psychology graduate program at Georgia State University and conduct research at the LRC.

When, as a graduate student, I finally had the opportunity to meet Duane, I was nervous and afraid that it might be an intimidating experience - well, not so! Duane was extremely interested in my background and my thoughts on chimpanzee cognition; and he wanted to hear all the details of my research. I found Duane to be a genuinely warm and intellectually generous person. As a Rumbaugh fellow, I was able to meet with him again on several occasions, and he would sometimes send an email to see what I was up to or to offer encouragement when I was looking for a faculty job. Duane was always interested in the research that each of us at the LRC was conducting with the apes and monkeys, and always willing to share his thoughts and advice.

Because of Duane's ground-breaking work with Lana and the symbolic language he developed for use with the apes, I was able to take advantage of a once in a lifetime opportunity to investigate the speech perception capabilities of the chimpanzee Panzee before her passing. I will always be grateful to Duane... first for unknowingly sparking my interest in ape language research, later for the privilege of being a Rumbaugh Fellow and getting to know him, and always for his kindness and generosity.

Lisa Heimbauer

Duane Rumbaugh's influence on my life and career was far stronger than the three years we spent working together at San Diego State College might suggest. He was directly responsible for my essentially biological, certainly evolutionary, approach to psychological science. He was the principal source of my comparative bias toward the interpretation of data on intellectual development and cognitive processes. He played a large part in building into my philosophy of science a reliance on strong inference, insistence on relevant data, and understanding of science as a cognitive enterprise supported by empirical observation.

I arrived at San Diego State in 1954 as a third-year undergraduate whose formal education had been interrupted by four years of military service-thus, as one who needed to relearn the art of being a college student. Convinced that psychology was what I wanted to study, and having had only an introductory course, I landed in Professor Rumbaugh's Introduction to Psychological Statistics, where I quickly learned the meaning and value of a no-nonsense teacher who had a not-so-carefully concealed human warmth. I got an A in the course, and have always suspected that it was because my wife was excelling in the same class, clearly an A student, and the professor did not want to be the cause of any domestic strife. I learned to respect data-and at least one psychologist. Other courses under his instruction followed: History of Psychology (with E. G. Boring's great textbook), Theories of Learning, and best of all, Comparative Psychology.

As a graduate student I served as Professor Rumbaugh's teaching assistant in comparative psychology (with Calvin Stone's text). Even though Duane was still a confirmed behaviorist, he instilled in me the beginning of what would become a permanent dedication to cognitive psychology. The students were skeptical of Köhler's famous "insight" demonstrations with Sultan, the chimpanzee, so Duane had me attempt to replicate them at the San Diego Zoo with Sadie, an 8-year-old chimp. When we were partially 
successful, and we had Sadie's accomplishments recorded on $8 \mathrm{~mm}$ film, then the students became reluctant believers. Every student in the class had to carry out an approved project at the zoo. One student was interested in knowing whether the great apes might respond with movement to rhythmic music, so she played drum music in front of the gorilla cages and filmed the apes' reactions. Another wanted to study a supposed dominance hierarchy in Galapagos tortoises-surely the slowest-moving project one could have dreamed up. All were held to strict standards of systematic observation, but their most valuable learning occurred around the interpretation of their data.

Rumbaugh's research was programmatic rather than episodic; that is, his search for knowledge was cumulative, each study built on and informed by what had been learned in previous studies and from consequent "emergent" insight. Thus, his demonstration of a species-sequenced progression in learning effectiveness across primates was a product of programmatic comparative application of his innovative tactical tool, the transfer index. Those studies also reflected Rumbaugh's recognition of the astonishing research opportunities available at the San Diego Zoo.

Duane Rumbaugh was a prolific developer of research tools. The transfer index was both a tool for investigation and an aid to interpretation of data. His most important tool-box contribution was the computer keyboard system of linguistic symbols (lexigrams) that became the instrumental basis for his and Sue Savage Rumbaugh's studies of language use by the great apes, especially chimpanzees and bonobos. His recognition of the importance of having the right tools with which to study intelligent behavior carried over directly to his development of theories for understanding the epigenesis of such behavior. Indeed, he emphasized the role of tools and familiarity with them in conceptualizing the development of learning abilities in primates. It was perhaps this kind of insight that led him to recognize that the "learning" principles based on operant conditioning, although inadequate as explanatory principles, constituted essential tools as research instruments, and he used them as such while developing far more important explanatory concepts.

As founder and director of the Language Research Center at Georgia State University, Rumbaugh and his colleagues instituted the startling practice of studying language and learning in both non-human primates and human beings with intellectual and developmental disabilities. These studies sometimes involved the same investigators and the same or similar tasks. I had the opportunity to serve as a member of the consulting faculty, which allowed me to see directly the value of this scientific alliance.

Rumbaugh's studies of discrimination learning, operant conditioning, and ultimately language acquisition and use culminated in his theory of Rational Behaviorism, which, true to comparative science, has provided an essential bridge between the intelligence of apes and human developmental epistemology. As Rumbaugh-behaviorist evolved into Rumbaugh-cognitivist, the two most important concepts of his rational behaviorism, salience and emergents, constituted a means of understanding how isolated incidents and $S-R$ relations are combined with tool use, prior knowledge, motives, and varied experience to bring about qualitative changes in cognition and ultimately creative behavior. The huge leap from conditioned reflexes to intelligent behavior has become less intimidating, more possible to achieve. Piaget described it; Rumbaugh explained it.

At a macroscopic level, Duane Rumbaugh's theoretical and empirical contributions applied the principles of comparative psychology to increase and enrich our understanding of intelligent behavior in the broadest possible sense. At the level of one individual, he was instrumental in helping a clinical psychologist through a research career in human cognitive psychology.

Carl Haywood 
In the early 1960's, Duane Rumbaugh and I were colleagues at San Diego State University (SDSU). In 1967, I left for two years at the University of Missouri at Kansas City, but returned to SDSU in the late summer of 1969. At the same time, Duane left for Georgia State University, so we agreed that I should buy his house. I didn't have the money to pay for it right away, but Duane very kindly agreed to wait for his money. I appreciated his kindness and confidence in me, and we became great friends as a result. (I did pay him.)

We kept in touch over the years, as Duane initiated the LANA chimpanzee language project, founded the Language Research Center in Atlanta, and became arguably the most famous animal language researcher in the world. As his research gained recognition, he remained the same generous gentleman who had allowed me to move into his house "on credit."

I visited Duane and his wife, Sue Savage-Rumbaugh, several times over the years, and Duane, after I retired, talked me into becoming a coauthor with him on an animal language book. We visited other language projects to obtain first-hand information for the book. He, or I, or both of us, visited Irene Pepperberg, Penny Patterson, Lou Herman, Deborah and Roger Fouts, and Lyn Miles. These visits were highlights of my life and, for all of them, I remain deeply grateful to Duane.

Duane and Sue boldly defended animal language research at a conference designed to defame animal language research by attributing its alleged findings to the "Clever Hans effect." No other animal language researchers attended. Later the conference organizer admitted to Sue that he had been wrong. I always felt that they should have been publicly recognized for their defense of animal language research; it is part of their great legacy. Sue recently told me that she intends to spend a great part of the rest of her life defending Duane's legacy. More power to you, Sue! Duane would be proud, but not vain!

\section{Al Hillix}

I was greatly saddened by the recent death of Duane Rumbaugh who had been a dear friend for over 40 years. Duane was a wonderful person, always generous and supportive with a friendly sense of humor. He had an enthusiasm for new creative approaches to his research on primate learning and cognition. He was once warned that he was "skating on thin ice" by making one of his more daring assertions. His apt reply was that "those who skate on thin ice are the first to fathom the depths."

After receiving his doctorate at the University of Colorado in 1956, Duane accepted a position at San Diego State where he became interested in Harry Harlow's innovative approaches to primate learning. The proximity of the San Diego Zoo provided an opportunity to extend Harlow's procedures to the great apes. Duane installed a modified version of Harlow's widely used Wisconsin General Test Apparatus in the walls of the ape enclosures at the zoo and over the next ten years produced a remarkable series of studies on the learning capabilities of apes as well as monkeys.

One of his most important findings during this period was a solution to the classic problem of measuring interspecies learning differences. The problem was that species differed in a myriad of ways that affected performance but not the underlying learning itself. His solution was the R/A ratio, a measure of performance on discrimination reversal problems relative to performance on the corresponding acquisition problems in the context of multiple discrimination reversal problems. Each subject thereby was its own control thereby removing effects of confounding species differences.

In 1971, after moving to the Yerkes Primate Center in Atlanta, Duane became intrigued by the dawning interest in language capabilities of great apes. He was the first to use computer technology for research into these capabilities. His computer-based procedure, incorporating abstract symbols, labelled 
lexigrams, and an artificial language, allowed two-way communication between a chimpanzee, Lana, and a human trainer. Lana quickly learned the basic grammatical rules and, most importantly was able to express novel sentences that were consistent with the grammatical rules. The success of the Lana project led directly to later ground-breaking studies by Duane and Sue Savage-Rumbaugh showing that bonobos could master many of most basic capabilities of human language learners. Interestingly, his research directly linked the pioneering research of Harry Harlow to the modern remarkable later studies of language using apes.

Duane will be remembered for his inspiration to all of us and his steadfast desire to contribute to unraveling the mysteries of the primate mind.

James King

I first met Dr. Rumbaugh fifteen years ago while working as a graduate research assistant at the Language Research Center (LRC). One of the very first things he did was hand me a copy of his new book, Intelligence of Apes and Other Rational Beings, with the inscription "To Emily! A fine young and promising student! With highest hopes and best wishes - Duane M. Rumbaugh." That book, in which he drew on his lifetime of work to hypothesize a new theory of behaviorism aimed at explaining the rational nature of learning, has traveled with me to seven different apartments and houses and still has a prominent place on my bookshelf. During my many years in grad school I frequently consulted that book when seeking a deeper understanding of learning and cognition and his personal message always made me smile.

My fondest memory of Dr. Rumbaugh was interviewing him for a graduate class paper on my "academic family tree," which involved tracing my academic lineage back through ten generations of psychologists. Dr. Rumbaugh was the mentor of my graduate advisor, Dr. David Washburn, and gave him both his assistantship and postdoctoral position at the LRC. As I sat down to start the interview, I worried that I didn't have enough questions and that there wouldn't be enough to say. Dr. Rumbaugh proceeded to talk to me for a full hour and a half about rational behaviorism, the history of the field of psychology, and his personal psychology, which emphasized the use of a comparative perspective to study both learned and unlearned behaviors in order to truly understand our own species. I learned that Dr. Rumbaugh was educated as a general experimental psychologist and believed that general psychology is the most important area of study for both undergraduate and graduate students. In keeping with this, he believed that students should all receive a solid education in the basic experimental method, as well as methods particular to their field. Looking back over the past decade of my professional career, I realize just how right he really was about this. I have worn many hats in the workplace, including human factors researcher for a telecom company, user experience researcher for an eCommerce team, and currently, medical researcher in the field of pediatric cardiology. In all of these positions, I constantly rely on the strong foundation of experimental methodology I received at Georgia State.

Although Dr. Rumbaugh is most known for his groundbreaking work with ape language, it was his development of a computerized training and testing system for rhesus macaques that had the most impact on my academic research. This system, in which a macaque manipulates a cursor on a computer screen using a joystick, is now widely used in behavioral research. It was this system (called the Language Research Center's Computerized Test System or Rumbaughx, pronounced "rum-box") that allowed me to conduct my doctoral research on numerical cognition in rhesus macaques. While I was at the LRC I was also fortunate to work with Dr. Washburn and Dr. Rumbaugh and several other investigators from different universities and institutions on a large project called Brain Behavior and the Emergence of Cognitive Competence (B2EC2). This multi-disciplinary project, which was designed to examine the development and emergence of executive attention, relational learning, numeric and symbolic processing, 
spatial problem solving, and metacognition across species, would not have been possible without the vision and hard work of Dr. Rumbaugh.

I remember Dr. Rumbaugh as a pioneer in the field, but also as a warm, funny, encouraging presence at the lab. His work and his mentorship have had immeasurable impact on my life, and the lives of so many others. I am thankful that I was given a chance to know and work with him.

Emily H. Marr

Professor Duane Rumbaugh conducted decades of innovative, scientifically sound research on nonhuman primate learning and cognition. His body of work profoundly changed the prevailing view of the learning, cognition, and intelligence of apes. Scientific understanding shifted due to his research, and paradoxically created challenges in the appreciation of its significance. Fully understanding the significance of Dr. Rumbaugh's contributions requires a review of decades of his research within the context of the predominant scientific thinking when he conducted his experiments. The influence of his training in experimental psychology at the University of Colorado is clear in his careful consideration of methodology of his research studies throughout the years. His interest and enthusiasm for the study and understanding of learning and cognitive processes also stand out.

Review of his contributions spans several productive decades of creative research that included studies of: (1) primate intelligence at the San Diego Zoo from the mid-1950s to 1969 while at San Diego State College; (2) language and cognition at Yerkes Research Center of Emory University from 1969 to 1971, including the beginning of the Lana chimpanzee language project that had the first computer-monitored keyboard with distinctive word symbols; (3) learning, cognition, and language at Georgia State University beginning in 1971, including the cofounding of the Language Research Center in 1981, and continuing until his retirement in 2000; as well as (4) continuing studies of primate cognition and intelligence by collaboration with professional colleagues and his writing and publication in 2013 of the book, With Apes in Mind, a compelling narrative on his personal experiences as a research scientist of primate learning, cognition, intelligence, and language.

An examination of his research shows an open minded scientist who learned from the observations of his research participants. The progression of his research findings demonstrates his reflection on the limitations of test apparatus and research design in revealing the capability of primate learning. His research career displays a psychological scientist's awareness of how a question is posed to research subjects clearly impacts what we are able to discover. Reflecting on his research provides a glimpse of how his openness to observing the unexpected responses of his research participants advanced scientific thought. The review of his years of research discloses how Dr. Rumbaugh and his partnership with the great apes contributed to the development of the emergent theory of primate cognition. This theory explains primate learning and cognition by complex learning and emergent processes in which the primates combine learned behaviors into novel, complex wholes. Primate learning and cognition, according to emergent theory, is more than only the conditioned responses as explained in traditional behavioral frameworks of stimulus, response, and reinforcement.

On a personal note, Duane Rumbaugh was my professor, mentor, dissertation chair, and friend. We met near the end of the summer of 1978. I was on the Georgia State University campus because I had been accepted to graduate studies in the Department of Education beginning the upcoming fall term. On a serendipitous whim, I decided to visit the Psychology Department. I ended up in the office of Dr. Rumbaugh since he was chair of the department at that time. We engaged in a lengthy discussion of our mutual passion of the psychology of learning, and when I left his office, I was enrolled to begin doctoral study in psychology the fall term. It led to some humorous moments a couple of weeks later at the 
orientation event for new psychology doctoral students where other students discussed their arduous tales of getting admitted to the psychology doctoral program. They then asked me about my acceptance, and I indicated that I met Dr. Duane Rumbaugh a couple of weeks ago and was now here. A chance meeting of Dr. Rumbaugh significantly impacted me and resulted in my career as a psychologist rather than an educator.

Our first research study together demonstrated mediated learning in human adolescents with severe intellectual disability. This study compared previous research findings on nonhuman primate learning. Dr. Rumbaugh had expected the prior performance of the nonhuman primates to exceed that of the human adolescents with severe intellectual disability, but the findings were contrary to his expectations. As always in his career, he saw where unexpected findings would take him. Research at the Language Research Center included experiments on the learning and language development of children and youth with intellectual disability. Dr. Rumbaugh was the chair of my dissertation on the effects of color on the learning of geometric symbols (lexigrams) by individuals with severe and profound intellectual disability. I also worked with him and others at Georgia State University on a major chapter that summarized research on primate learning, problem solving, cognition, and intelligence up until the mid-1980s. After my doctoral studies, I went on to postdoctoral study of cognitive psychology and intellectual disability, a public service career in state services to individuals with intellectual and developmental disabilities, and more recently, teaching undergraduate students in psychology.

For over 30 years after my graduate studies at Georgia State University, Duane and I remained friends and in touch by phone, email, or in person. He often sent me manuscripts to review and always appreciated my input. I last spoke to him in February 2017 and enjoyed the opportunity to reflect with him on his numerous contributions to the field of psychology.

As I teach undergraduate students research methods and the psychology of learning, cognition, and language development, I often think of Duane. His life work continues to touch others even as he is personally missed.

Darlene Meador-Osborn

I first met Duane over dinner in San Diego in June 1983. Although a mid-westerner by birth and a behaviorist by training, Duane had found his proper life space that week. He was proximate to the worldfamous San Diego Zoo where he had begun his primate learning studies. He was overlooking the ocean by Sea World, home to fascinating large-brained creatures. And he had been invited to discuss great apes with colleagues at a naval research conference on dolphin cognition! My future wife, Jane, and I were there on a family vacation as guests of Emil (also attending the conference) and Harriet Anne Menzel. We greatly enjoyed Duane's conversational charm and humor, as well as the opportunity to meet and talk with Sue Savage-Rumbaugh. My grandmother, also there, treated the occasion as if it were a southern dinner party. When Duane and Sue, scientists with formidable credentials, arrived at the table, they graciously complied with her firm verbal and manual pointing instructions on where to sit! Chimpanzees, animal intelligence, and primate fieldwork soon were among the topics of discussion. I remembered this positive experience, and many years later when Duane offered me a research position at the Language Research Center I gladly accepted.

In 1996, I learned from Duane's invaluable assistant, Judy Sizemore, that it was considered proper etiquette for new employees to bring a viable grant proposal to the LRC research party upon arrival! I soon found that it also was customary to review one's progress with Duane over lunch at Decatur's Piccadilly restaurant. Eventually, I reported that a proposal had evoked a nibble of interest from a federal agency but that it was right around the funding cutoff line. Duane said to call my program officer 
immediately! I should let him know that I was "ebullient" about starting the research, adding: "enthusiasm is contagious!" I had never before uttered the word "ebullient." Nevertheless, enthusiasm I did convey, and we were delighted to get support for a chimpanzee memory project. Duane remained unfailingly supportive of this research well beyond his retirement, an example of his generous spirit.

The LRC attracted a constant stream of scientists, and our conference room stayed active. A team from NIH arrived on the grounds to witness a new form of chimpanzee testing. Duane had gotten all of us excited. He coordinated the action from his cell phone as he strode back and forth in front of the building where the apes were housed. The promise of the new test results was palpable! The visitors, caregivers, and staff researchers gathered around the window. Naturally, there was so much human excitement that Panzee chimpanzee flatly refused to participate in her official testing that afternoon. For Duane, this was an important lesson, one that we often had to relearn: when studying the creative behavior of a great ape, do not press, and find ways to let the ape take the initiative.

The commute to the LRC is the most beautiful in Atlanta, with more than a mile of forest between the gate and the main building. We often see wildlife in the evening. Duane would stop his jeep while leaving the lab to announce by two-way radio "there's a box turtle sitting on the road; be careful when you drive out!" He sometimes moved the turtle off the road, but not always, sometimes allowing it to remain there for others to appreciate. Duane loved animals and trusted people to be responsible stewards.

In 1999, Duane had laryngitis, so several of us from the LRC gave guest lectures in his introductory psychology course. I was in class shortly after the Columbine shooting incident. Duane spent the period discussing the event and exhorting his young students to view themselves as psychologists, to have something to say about such problems, and to find ways to prevent them.

Duane also encouraged us to speak up about less critical social and scientific issues. In 2011, I was preparing to give a talk on the necessity of chimpanzee behavioral and cognitive research at a national meeting. Needless to say, I wanted the presentation to go well and asked Duane's opinion. Duane offered this as food for thought: "We have learned more about the origins, the genesis, of creative behaviors in the last 50 years through studies of great apes than what we have garnered through the studies of children or other forms of animal life. We are at the bedrock of genius, we are at the bedrock of creative behaviors, and we want to see our country as being wise to selectively protect the use of animals in behavioral research, and notably the chimpanzees ... the great apes." For Duane, the full range of primate species are to be appreciated and studied carefully, and he compared great apes in particular to gems and precious metals and good investments that should be protected. Duane's recognition and deep appreciation of unique animal resources is important for research today.

Charles Menzel

Dr. Duane Rumbaugh's contributions to the field of comparative cognition and the psychological sciences heavily influenced my graduate training and continue to shape how I think about and approach questions of primate behavior and cognition. Duane's work on primate learning, ape language, and emergent behaviors is pivotal to our understanding of monkey and ape intelligence. He called for a Rational Behaviorism that allows for the development of relational learning and emergent behaviors alongside conditioning and a species unique evolutionary history. Importantly, these emergent behaviors are critically dependent upon underlying cognitive processes. Duane argued that evidence for emergent behavior exists all around us, if we just provide animals a means for communicating that information.

One of my greatest joys in working at the Language Research Center has been watching for these emergent behaviors - the "a-ha!" moment, in chimpanzees and monkeys. I started working at the LRC 
shortly following Duane's retirement, but I've had the great pleasure of meeting him at the lab and seeing him reconnect with his beloved language-trained chimpanzees over the past few years. I remember one of his visits, where I had the chance to go visit the chimpanzees with him, and to see how Sherman, Lana, Panzee, and the other chimps interacted with Duane, who they had not seen in a couple of years. That was a wonderful memory, and a thrilling chance to see Duane with his chimpanzees.

Duane Rumbaugh's scientific contributions to the field were matched only by his love for science, his humor, and his incredible generosity. I am honored to serve as a recipient of the Duane M. Rumbaugh Fellowship award that supported my dissertation work at Georgia State University. I am forever grateful that Duane showed such an interest in my work with the LRC's chimpanzees, and an interest in my own development as a scientist. I know I am not alone in having received such attention from Duane, and I am thankful to be counted in the great company of Duane's students, colleagues, friends, and family.

Audrey Parrish

I met Duane Rumbaugh during the 1970-1971 academic year soon after he became the Associate Director of the Yerkes Regional Primate Center in Atlanta, Georgia. He had applied for an adjunct professor position at Georgia State University, and at an interview party, I suggested that he change his application. I was chair of the Chair of the Department of Psychology Search Committee, and Duane applied for the chairmanship, which he received. I subsequently was chair of the Rumbaugh Chair Retirement Committee, and thus, I was involved with him at the beginning and the end of his chairmanship. I often have stated that my major contribution to the department at Georgia State University and to psychology was my convincing Duane to apply for the chairmanship.

Although Duane probably is best known for his research and theories regarding language-like behavior, his earlier research was innovative and was a significant contribution to understanding discrimination learning. His development and use of the transfer index provided truly comparative research in that the same index was used across a significant variety of non-human primates. Fortunately, he invited me to join him on in analyzing and interpreting combined research findings from numerous investigations. His unique approach to the investigation of language-like behavior in chimpanzees, beginning with Lana, was insightful and changed in many ways the study of language. In his research, he produced "big data" before that was a catch-phrase. He also demonstrated the usefulness of computers in that they provided a new way of interacting with non-human primates and allowed for the collection of a tremendous amount of data. Again, I was fortunate to be involved in some of his research in this domain as well.

As a department chair, he was supportive of the faculty members and aided them in becoming better psychologists. He managed to continue his research program during the time that he was chair of the department, an unusual achievement in that chairmanships often divert people from their research. The students who studied with him continue to make numerous important contributions to research, education, and leadership in various psychological organizations. Duane's leadership was not restricted to the department or college level, and he was instrumental in guiding scholarly organizations. He served as president of the Southern Society for Philosophy and Psychology and as president of Division 6 of the American Psychological Association. In both, he found ways of enhancing the membership and the programs of those organizations.

Duane was an outstanding colleague, a very effective chair, a productive researcher, and a great friend.

James Pate 
I had the great pleasure of getting to know Duane Rumbaugh when I was a postdoctoral researcher at the Language Research Center at Georgia State University. During that time, I benefited both directly and indirectly from the influence of Professor Rumbaugh. Although Duane was no longer living in Georgia, he came to visit several times while I was working there. I got to know him over lunches at the Piccadilly Cafeteria and many email exchanges about the capacities of the animals with whom we were working. In addition, his influence as a mentor was also felt in more indirect ways. My postdoc mentor was Michael Beran, who himself was shaped and influenced by Duane and shares many of the traits and qualities that made him such an effective mentor. I feel lucky to have felt his influence in many ways and recognize the significance of his contribution to my academic development.

I was honored to be the 2012 Duane M. Rumbaugh Fellow and worked closely with Duane on several projects during my time as a fellow and in the following years. One of the projects that clearly reflected the combined influence of Duane's and my interests related to monkeys choosing to choose. We carefully controlled for reinforcement differences and still found that monkeys prefer having the power to make choices. Working on this project, and others, with Duane, reflected several aspects of his personality that helped him to be such a successful scientist and mentor. First, he was very thoughtful and intentional about research design. Second, he never lost sight of the big picture even when focusing on the details. Finally, he believed in people (and the animals!) and was always encouraging, optimistic and supportive of those around him. I am grateful for those lessons and the time I was able to spend with him.

As many know, Professor Rumbaugh advocated for emergents as a class of behavior that goes beyond traditional forms of reinforcement. In a sense, the idea is that sometimes the whole is greater than the sum of the parts. In many ways, this also reflects the influence of Duane M. Rumbaugh. His lasting and far-reaching influence goes beyond his individual interactions and contributions. His influence has and will continue to transcend the individual parts to reflect a much greater contribution - an emergent life that will continue to influence the field and the people working in it.

Bonnie M. Perdue

I became acquainted with Duane at the University of Colorado during the academic year 1953-1954, while Duane was finishing his doctoral work, and I was an undergraduate major taking experimental psychology. He was good friends with the lab instructors, Wes Zaynor and Pat Capretta, and would stop in to see them after labs. I believe it was there we were introduced, and I remember being involved in various conversations with them. I also remember talking to Duane and Phyllis, his first wife, at several joint Psi Chi - Graduate Club parties, probably because my wife Paula and Phyllis hit it off so well. The second semester of the experimental course was taught by Duane's dissertation adviser, Maurice Smith, and that half of the course was about learning with an emphasis on reinforcement. Although we learned about the whole gamut of neobehaviorist theories and related research, somehow the Hull-Spence theory held prominence, probably since Smith was a student of Kenneth Spence. So, Duane as a student of Smith was well schooled in this tradition, as was evident in the title of his dissertation. Although he moved away from it particularly as the ape language research progressed, there were still tendrils and reverberations of Hull as I read several drafts of one of his last books, The Intelligence of Apes and Other Rational Beings (with David Washburn).

After Duane moved to Atlanta our lives and people in them were intertwined. I will mention some events and people to illustrate this. One day in 1969 - 1970 a friend, Al Pieper, told me he would like me to meet the new associate director of Yerkes, where Al was engaged in research with chimpanzees, and suggested we all have lunch. They picked me up at home in Duane's car. He was wearing a rather broad brimmed brown fedora hat making it hard to see his whole face. It began dawning on me as we drove to 
a nearby deli that I already knew him from somewhere but not in that hat. Sitting in the deli we reconstructed that we had become acquainted at the University of Colorado.

The following year the job of chairman of psychology at Georgia State University (GSU) became vacant and Duane interviewed and was hired for it. In the spring before assuming the position he started looking into departmental affairs. Among other things he discovered that I was up for tenure the following year. He took immediate interest in my case. I was nearing final submission of my dissertation research for publication, but Duane thought my credentials were lean and he urged me to find other things to publish. Duane then began regularly checking my progress, encouraging and cajoling me in his positive friendly way. I managed two more papers in the following six months, all three were accepted, and I was granted tenure. Although sometimes I felt Duane was emulating Simon Legree during that period, he insured that a positive outcome of tenure was achieved, and it probably would not have been without his efforts.

In subsequent years I inadvertently supplied Duane with two important support persons for his increasingly computerized research efforts. In the year before he came to GSU I had received the go ahead to develop a 1970s state of the art EEG lab. One of several people who helped me put the lab together was S. Tom Smith, who first worked in the lab as an undergraduate and then proceeded to do an M.A. thesis with me. Along the way he learned to program the department's IBM 1800 data acquisition computer, which was one of the main reasons I was attracted to Georgia State. Tom was remarkably adept with computer technology. Duane discovered this I believe in 1974 or 1975 and hired him forth with. I hated to see him go, but he still continued to aid my research efforts through the next decade. He also provided a conduit so I could keep up with what was going on in Duane's camp. I was increasingly impressed with the research results from the keyboard technology with not only the chimpanzees following Lana, but also the severely mentally disabled children in Mary Ann Romski's research program. Tom along with his biomedical engineer partner from Emory/Yerkes, Victor Speck, enabled all of that research.

In the mid 1980s, Tom was burning out and wanted to go into business for himself. Duane needed a replacement. A bare faced David Washburn had arrived at GSU for a year to take courses not offered at his alma mater, Covenant College. He wound up in my fall cognitive psychology class, and for the rest of the year became a valued part of my lab personnel. David had acquired an extensive knowledge of commodore computers in high school, and had become quite a programmer. He went back to Covenant to finish his last year, but to my delight he decided to come back to GSU for graduate work in human cognitive psychology with me. Duane, always astute at filling personnel needs, discovered his computer aptitude and offered him a full time graduate research assistantship, replacing Tom Smith. This gave David the support he needed to come to graduate school at GSU. As a result, David had to juggle his LRC job with the pursuit of human cognitive psychology working with me on his thesis and dissertation, effectively two full time jobs. As David will tell you, his affiliation with Duane was of immense value in his education, and it has stood him well in the vagaries of life as a research psychologist.

I will continue with several sort of amusing vignettes. In the year before Duane and Sue published their 1978 BBS article it became apparent that David Premack and Donald Griffin were going to author the other articles in the same issue. Duane knew that I had done my M.A. thesis with Premack, and we had discussed my experience at some length. He had received notification from the editor that Premack had requested that his article be the first in the issue. Duane went out of his way to tell me about this with some amusement. There ensued some back and forth, since Duane didn't see any good reason for Premack's claim to primacy. During the next months, Duane, not losing his good humor about the matter, kept me apprised of each development. Finally, Premack playing his alpha to the hilt won his place despite Duane's objections on the phone with the editor. 
Several years later Duane organized two symposia for the 1981 Southeastern Psychological Association meeting surrounding ape language research but also including papers on human cognition and language development and other topics. Duane knew of my interest in the concept of intention, a topic which was just beginning to be cautiously explored in psychology, but which had quite a history in the philosophy of action. Because of the blow back from attributing intention to apes in the 1978 BBS article, he asked me to write a paper supporting that assertion. Inadvertently that task would also defend the same attribution by Premack and Woodruff from that same issue referred to above. Of course, it didn't help with their attribution that chimpanzees have theories of mind. I had found that the core concept of intention according to some philosophers of action was "aiming at an outcome" in the sense of directing oneself towards it, which made a lot of sense to me. Therefore, I decided to entitle the paper "Do Willful Apes Know What They Are Aiming At?" Duane couldn't abide that title with a terminal preposition. He repeatedly asked me to find another title, but to no avail. Aiming at nicely expressed that core concept. He was still regretting the title when I published the paper in 1985. Unlike his strait laced Iowa English, mine (also from Iowa - age 4 to 14) had benefitted from association with poets over several decades and could tolerate the transgression.

Duane was certainly a great asset to GSU. His innovative research programs and his support for others working with him led in a number of interesting and informative directions. His administrative skill in simultaneously running a large complex department and a substantial research operation was remarkable. Few know of the machinations Duane went through to plan and realize the founding of the Language Research Center, which required careful balancing of multiple interests. As the plans progressed he told us of the political and legal problems of merging a public entity, GSU, with a private one, Yerkes as a branch of Emory University, all of that with the stipulations of the federal government, which had donated the land to GSU. It was really a magnificent accomplishment, when it was done, and a wonderful resource for studying primate cognition.

Unfortunately, I did not see Duane very often after he and Sue moved to the Great Ape Trust in Iowa. Duane was a good friend and his good humored collegiality has been sorely missed.

\section{Tom Putney}

I first met Duane Rumbaugh following his presentation on Lana at the International Primatological Society in 1974. The highlight of that August gathering was Duane's presentation about Lana chimpanzee. Five hundred people from around the world, all of whom studied primates, were there for Duane's presentation. Duane's talk was brilliant, entertaining, modest and sparkling - as always- but this was the first one I had ever heard. I was astonished at his descriptions and brief clips of Lana. I was a graduate at student at the University of Oklahoma at the time and working with Washoe, Booee, Bruno, Lucy, Nim and many other chimpanzees. I had already learned that rearing and method made a big difference in what apes became - but I had seen nothing in any of the 40 Oklahoma chimpanzees (all with very different rearing backgrounds) that was anything like what Duane was reporting for Lana. I did not know what to make of Duane's recounting of Lana's conversations with Tim or the long syntactically correct sentences she regularly produced. It seemed that she was in a different category of beings than the chimpanzees I knew in Oklahoma. So I gathered up my courage and went up to stand in line to complement Duane on his work. After a long wait, I finally got my chance. He was so very kind, nice and polite and willing to listen to a graduate student who had yet to publish a thing...quite unlike other well-known figures who had not given a student from someplace like $O U$, the time of day. I tried to tell Duane a bit of what I had learned about apes and language from the chimpanzees in Oklahoma - and especially Lucy - who had just adopted a kitten as pet. Little did I know at the time that Duane had been a reviewer of my paper on Lucy and her kitten and had even recommended its publication, though other reviewers turned it down. 
I was surprised at how courteous Duane was, not only to me, but to everyone. This, I was to learn, was part of the wonderful essence of Duane Rumbaugh, along with his humor and his quiet genius, and this graciousness affected every single person he ever knew. Long before I actually met Duane, I had begun reading his work on primates. I studied his transfer index work in detail from my first year in graduate schools at the University of Oklahoma, not because it was presented to me in my course work, it wasn't. But I found it while reading other things and became a true and dedicated student of Duane's transfer index and learning set work even though I did not know him and no one else at OU seemed to be aware of his work.

I had elected to attend OU instead of Harvard once I found out that chimpanzees could learn language and were doing so in Oklahoma. I reasoned that - IF it was really language it had to be something "more than conditioning." And I began to realize that if I wanted know what that something might be, I needed to fully understand Duane's work on the Transfer Index, Harlow's work which preceded it and the Lana work which followed it. This seemed the only logical way to approach these myriad attempts of the 1970's to determine whether or not apes were capable of language. It seemed to me that these were the most important questions that psychologists could address. I felt fortunate to be around so many chimpanzees with different rearing backgrounds.

I could not understand why the other psychologists at OU did not see it this way also -- but that did not matter at the time-- because it was clearly true and I was very young. As an eager student, I was firmly fixated on learning the "truth" of things and had no concept of the politics of science. I believed the text books that talked about the noble profession of science. And Duane Rumbaugh - throughout his life perfectly embodied that noble concept science. I was truly blessed to meet him. I was to learn that very few others valued the search for truth as Duane did. In his world, there were no compromises or short cuts to truth. I admired that!

When I actually got the chance to meet Duane Rumbaugh in Japan - I wanted to tell him how much his work and that of Robert Yerkes had meant to me. I tried, but felt as though I was so nervous I could not do a good job. Much, much later he was to tell me that I made quite an impression on him, coming up and taking about Washoe, Lucy, the Transfer Index, learning set and all of the novel behaviors I saw in Lucy, including her ability to imitate complex actions on a trial one demonstration. But, at the time, I was not aware and was afraid that I been way too forward in trying to speak about my work to such a great scientist.

I did not hear from him after that until a year later when he invited me to give a talk at the Southeastern Psychological Association in Atlanta - which he was chairing. So again I saved up all my money and took myself to a meeting to find out what "real" psychologists did. I decided to present a paper on Pancho, a chimpanzee who had been reared by a zoo-keeper's family in a small zoo. Pancho was an adult male chimpanzee, but an unusual one in that he had webbed toes and his vocalizations were different than the other males there. Pancho seemed to be able to communicate everything that Washoe, Lucy, Booee or Bruno could communicate to me, but he had not been taught ASL signs. I was beginning to realize how much human communication depended upon common interpretation of context and the small nods, gestures, glances, etc. that communicate so very much when we are already interpreting the world around us in a similar manner. So my paper dealt with how Pancho - who had acquired no "formal" ASL signs to communicate so well in fact, that he and I could drive around Norman, Oklahoma and even go to the A\&W Root beer drive-in and be served, with no difficulties. Indeed, no one there even thought it was the slightest bit unusual. He also understood English though I did not know enough at the time to measure this or even how to do so. And, also, I mostly was quiet around him because I was taught that chimpanzees could not understand English and one was supposed to sign to them, as if they were deaf. To my surprise Duane approved the paper though it was not specifically about language. 
I had heard that were more than 150 chimpanzees in Atlanta. I badly wanted to see them because I had been learning that all chimpanzees were very different - either because of their subspecies, their rearing, their group housing or something as ineffable as that which makes every human different. I was not sure. I also wanted to see the bonobos who had just arrived from Congo. I wanted to know if they were different from the bonobos I had spent weeks studying in San Diego. The bonobos at Yerkes were recently wild caught but the bonobos at San Diego zoo had mostly been born there from birth or were caught before the age of one year.

So I dared to mention this hope to Dr. Rumbaugh when I arrived in Atlanta. Duane had been the Assistant Director at Yerkes and knew it well. Much to my surprise he took me to the Yerkes great ape wing. We walked up and down the wing and looked at all the chimpanzees while they threw feces at us. His gait was jaunty - as though he were still in charge there, and in some ways, he was. I was so astonished at seeing hundreds of chimpanzees - each of which was so different from any other chimpanzee that I had ever seen I did not even think to ask to see the famous Lana. Later I was chagrined because I had wanted to see Lana. But, at the time, all I could do was stare at the hundreds of chimpanzees on the wing. We could not see the bonobos because they were still in quarantine - but I did get to see the nursery chimps.

The fact that I was so fascinated with the behaviors of these chimpanzees living two to a cage on the Yerkes wing - and that I had spent weeks in San Diego - alone - studying the behavior of bonobos there, must have impressed Duane because he called months later to offer me a post doc position at the Yerkes Center. Much later, he told me that no one had ever asked to see all the chimpanzees at Yerkes before...just to see them as individuals. Some scientists were very interested in the behavioral repertoire of free ranging primates, but not captive chimps. In fact - not until Frans DeWaal began his work with chimpanzees in Arnhem and later at Yerkes would other students actually become interested in learning from the behavior of apes. When Duane called to offer me a post doc position at GSU to do work at the Yerkes facility, he also asked me if I might also want to do some work with Lana and the four younger chimpanzees there who were beginning to learn language. I am somewhat embarrassed to report that my answer was an emphatic No! I did not want to study language in chimpanzees, I had seen enough of that during my four years in Oklahoma, and I did not have faith in it.

I wanted to study the behavior of chimpanzees on the wing, the bonobos when they got out of quarantine, and, if possible, bonobos in the wild. There was so much to be understood about apes and they were so closely related to us and they were deliberate, thoughtful, intentionally and clearly communicative in a symbolic manner, whether it was "language" or not. I could not quite grasp why every primatologist did not see this. Fortunately for me, Duane did see it.

Duane first began to understand this in the 1960's when the huge male (Albert) did not like the fact that he switched the rewarded stimulus in his hand presented transfer-index apparatus. Albert responded by leaving a 3 dimensional fist print in the 1-inch bullet proof glass Duane had used. Duane knew that this was not simply an emotional response - it was a direct intentional message to him - from Albert. And Duane got it. He "retired" Albert after this, becoming the first to use the word "retired" for an ape who had "worked" in psychological studies. Duane respected and appreciated Albert's feelings even though Albert was a gorilla. Duane was thus among the first to realize that apes were capable of intentional symbolic communication and that a gesture - even a forceful gesture could be packed with a symbolic message. Duane often said that Albert did not appreciate the fact that the stimulus/reward contingencies were reversed. And when Albert saw that Duane had done this, he did not keep responding as though he did not know, nor did he switch because he "got it." Instead Albert gave Duane a message for doing it saying "You son of bitch - that's not fair." While this interpretation may seem passé now to some, at the 
time, it was extraordinary. Duane did not publish such an "anecdote" in a psychology journal. He published it in ZooNews. And it was one of the very first studies he described to me in great detail.

Luckily for me, Duane did not insist that Ifocus on the language studies - he allowed me to do what Ifelt was important. But he was having difficulty with the four new chimpanzees in the language project and with Lana. None of the four new chimpanzees (Sherman, Austin, Ericka and Kenton) were learning symbols and they were looking at them. And Lana was having trouble in the new building as a result of having the sentence length on her keyboard increased from five to nine words and her keys made much smaller, and she was looking at them. Yet her utterances were beginning to sound like word salad something that had not occurred before. With things unexpectedly floundering, Duane requested my assistance. His new grant had been in effect for two years and was not producing results. His previous research with Lana had begun producing remarkable achievements as soon as Tim had been allowed to go into the room with Lana. I agreed to spend some time in the new building, and so I began to focus on the language issue once again but in an entirely different way.

This led to many lengthy discussions between Duane and myself about what the difficulty was and what should be done. I had come from a "signing" project and the entire use of a computer based system was new to me -- but the chimpanzees at Oklahoma were also in social groups and I had focused on investigations of social behavior. I agreed to assist if I could --not realizing that this was to become a third defining moment in my life and a complete and lasting fascination with the process of language, its relationship to social interaction, the importance of dialogue, the effects it has on consciousness, the establishment of the self, the capacity for self-reflection, self-control and the building of cultural modes of beingness.

One task in which Duane sought to find the limits of emergent processes was that of numbers, both quantity per se and counting. He sought to take Lana into the realm of human counting and he sought to take monkeys into the realm of ape quantification and counting. Both goals proved somewhat elusive. Counting is a special and peculiar part of language, in that it does not typically involve dialogue nor does its symbolic aspect have any relationship to "things" or to the kind of relationship between "things" that syntax encodes. Many human cultures do not count beyond one, two, many. Thus, counting is not the remarkable God-given capacity often attributed to human beings. Another task that was never to come to fruition was the goal to provide, in monkeys, some aspect of language. Possibly this was because all such attempts never included the bonding, a social aspect of the phenomenon of language that is essential for all humans and all apes. Today, we still do not know if it is possible for monkeys to acquire a modicum of language, nor do we fully understand how the lack of capacity for self-reflection and/or to understand one's own reflection relate to the absence of language in both human children and monkeys.

Scientists of Duane's caliber are few and far between, but when one comes upon them, one always finds that they are ones who are constantly asking the 'big' questions. They are also the people who try their best to employ everything they learn to find the means to build a better world for ALL of humanity. Duane did this with every waking breath. And he never ever stopped - even as his body and short-term memory began to fail him, he continued with that same quiet grace and dignity. This was/is the essence of his being and with every hardship (which were many near the end of his life) this aspect of Duane grew stronger. His father had been a minister - Duane wrestled constantly with the discrepancies between science and established religion. As he drew closer to the end of his career this question occupied nearly all of his attention. And as it did, he made the most rapid progress of life to the peace that passes understanding.

Duane's legacy is not limited to the research he produced, it is greatly increased by all those whom he inspired; through his work, with the essence of his honesty and his magnetic personality and the wonder of "learning" itself -- something that most everyone who contacted Duane began to understand after time with him, because he always explained this to us in ways that made us want to understand it more. 
Duane's grasp of the role of learning exceeded that of any other psychologist I have encountered. He knew it insidelout and I came to "learn" much of what he knew from our constant conversations about the "work." They lasted from morning to night and were present at every meal. We never spoke of other things with the interest and intensity that were poured forth every waking moment into the explorations of learning and language.

Much of what has been learned has not even been placed properly within the ontogenetic research trajectory that emerged organically from the combination of language/learning/computers and cognitive studies. Duane had much left to say. I promised him that the work will go forward and that, with the help of many others, his contributions will be framed in a manner that is comprehensible and usable by all seeking to truly understand learning, language and consciousness. This is a very big job, but necessary so that all the "Rumbaugh Fellows" of the future have the tools to continue to take this truly remarkable research trajectory forward.

This requires replication, extension and increasing theoretical sophistication. None of this is easy but it offers to psychology a most remarkable avenue forward, if correctly understood and expanded. It is all too easy, and most often a "fall back" position to ask the same kinds of questions over and over, with a slight variation in technique or question - for this is always "acceptable" in science. This is not what Duane did. His mind was always seeking to integrate the large swaths of knowledge from his own work and that of others in an explanatory framework. For those of us who were blessed to know him, it is much like the blind men discovering the elephant. We each felt a piece of the great mind of Duane Rumbaugh now it is time to work together to discover the elephant, realizing that each piece matters, but what matters most is the whole.

Sue Savage-Rumbaugh

Duane Rumbaugh was a visionary. He conducted experiments with a range of animals at the San Diego Zoo and published several volumes that helped us begin to understand the cognitive skills of a range of species. He moved east to become the Associate Director of the Yerkes Regional Primate Research Center at Emory University. There, he created the LANA Project and designed a computer-linked keyboard with which a young female chimpanzee, Lana, acquired symbol meanings and sequences. His work continued with additional chimpanzee subjects, notably Sherman and Austin. His ultimate achievement though was the creation of the Language Research Center (LRC) in the early 1980s. Duane convinced a group of university administrators at Georgia State University and leaders of Emory's Yerkes Regional Primate Research Center to develop a distinctive laboratory in an area of Atlanta known as Panthersville. The motto of the Center: "so that together we might learn of language" embodied the best of Duane's comparative studies. Continuing the work funded through a National Institutes of Health Program Project, the facility was located in a 55-acre forest in the area and was, in and of itself, a unique entity offering both a human and a nonhuman side for the research conducted. It physically brought together work with youth with cognitive and linguistic disabilities and great apes whose symbol training and experience offered an animal model for the development of symbolic communication skills. The original Yerkish symbols were used to represent referents for learning and communication for both species.

At the LRC, the ape family was expanded to include the bonobos, Matata and then infant, Kanzi. In addition to important fundamental findings about symbols, how they are represented, learned, and used, there was a significant contribution of technology to this work. With the explicit focus on animal model applications, Duane and colleagues developed a "portable" keyboard that was built into a Samsonite suitcase providing a first transportable communication system. Over time, efforts to make speech output systems a reality were achieved with keyboards and speech shrinking in size, weight, and 
type. In our contemporary world, where Siri is available at a moment's notice to answer our queries, these advancing developments in technology were not trivial.

Later, Duane created a project, supported by NASA, to explore the impact of weightlessness on cognitive performance with monkeys as astronaut analogues. Again, Duane was at the forefront of a problem involving learning and cognition and worked to creatively explore and solve it.

One of my most significant memories of the LRC is that it became a hub with scientists from all disciplines coming to visit, learn, and interact. From Carl Sagan to Jane Goodall, Panthersville was the destination for people wanting to explore human and nonhuman skills and their relationships. It was a wonderful experience.

From his roots of studies of comparative learning and intelligence to the study of symbol acquisition and use aided by technology, Duane's work propelled the study of psychology and its application in provocative and critical ways. Duane Rumbaugh was a visionary.

\section{Rose Sevcik}

\section{Words to live by}

In his long and accomplished career, Duane Rumbaugh wrote and published nearly 200 articles and chapters, including those that filled the books that he authored. He taught countless students in the many classes that spanned his half-century career as an instructor. He gave hundreds of professional presentations, invited addresses, and colloquium talks. Across these outlets, he has spoken or penned some of the most insightful, original, cogent, and influential words in the history of our field. We all benefit from these contributions. But in the weeks since his death, I have also pondered some of the other things that Duane expressed to me over the years. These were not the profound declarations of "Duane Rumbaugh the renowned scientist and highly effective administrator," but rather some everyday utterances of a man whom I was privileged to call a mentor, employer, role-model, and dear friend. At risk of over-interpretation, I recount here a few memorable things Duane told me, and my recollections about his character that each illustrates.

"You should drive a truck."

Our first meeting, on my first day as a graduate research assistant under his direction at the Language Research Center, was typical of so many conversations to follow. We had spoken on the phone but had never met in person, so I introduced myself, apologizing for underestimating the commute time through traffic. He responded by extolling the virtues of an old truck for navigating the city, noting that it would offer more protection - and some degree of intimidation - against the typical Atlanta driver. I remember being surprised by how direct and persistent he was, particularly in our first conversation, particularly about a non-work matter. Only after I promised that I would try to follow his advice at first opportunity did he hand me the draft of a manuscript he was preparing to submit for publication and instructed me to be prepared to discuss it with him over lunch.

This would be the first of many occasions in which I received counsel from Duane. Although he was never my academic advisor, he had convinced me to attend Georgia State for my doctoral study, in part by providing the funding for my stipend. Accordingly, he took a personal interest in my life, academic progress and career. His grants funded my graduate assistantship every year of my training, as well as my first postdoctoral position thereafter. He convinced me (despite considerable resistance) to add comparative studies of rhesus monkeys to my research interests in human cognition-a decision I have 
never regretted. He forced me to complete my dissertation, else I might have enjoyed the life and work of a graduate student in perpetuity. He guided each step in my professional career, and groomed me to succeed him as Director of the LRC. Among his many professional lessons, I have tried to remember his approach in evaluations (e.g., grant or manuscript reviews; student or staff evaluations) never to lose sight of all the good things by nitpicking all the ways they might be made better. "Things can and should always be improved," he would say, "but we hurt the field by focusing so much on the small things that might be wrong that we forget the big things that are done right." Our discipline would benefit from refocusing on the impact of good science, good teaching, and good work, rather than undermining this impact with debate over the minutiae.

"Graduate students should go to all-you-can-eat buffets whenever possible. They never know how long it will be before their next good meal."

It was at the aforementioned lunch on that first LRC day that I received this pearl from Professor Rumbaugh. With a pregnant wife and a stipend of \$8,000/year, I certainly took the message to heart (and to waistline!). That pizza buffet was the first of many times Duane would treat me and other students at the LRC to lunch - the nearby Piccadilly cafeteria was a favorite of his - and his generosity was manifest in many other ways as well. He was also generous with his time, attention, and energies, as in the time that he intervened with the university on my behalf when I was denied insurance coverage for the birth of my second son.

After my father died, Duane frequently filled the fatherly role for me and my wife, and a grandfatherly role to my children. He had children and grandchildren of his own, and I don't pretend that he saw us that way; but my family certainly saw him in that light. He showed care and support for us in material ways, for example by providing money to help my children pay for college textbooks, and also in more important psychological ways, by providing sage advice, constant encouragement, and the occasional "back in my day" story that helps to ground each generation in a history that is otherwise all too easy to forget. He and my wife adored one another, and I am grateful to Joan and the rest of his family for the love and acceptance.

He was always good to me, but I am not alone in this regard. Duane was a people-person. He cared deeply about others. Our last conversation was typical of so many others: After begrudgingly giving me a real answer to my questions about his health and wellbeing, he wanted an update on how all of his friends, human and chimpanzee, were doing. Once the long list of former students, colleagues, and research animals had been discussed-and after he had pitched a new research idea to me for data collection with the monkeys! - we exchanged expressions of affection and I was instructed to convey his greetings and love to each of those friends. Those were fitting and precious final words for me to hear from him.

As I said to Duane on many occasions: His contributions to science will live on forever, but his real legacy is the people whose lives were changed by his influence, and the students/collaborators/friends who will in turn be influenced by those people, and so on. Generations from now, there will be individuals who can proudly trace positive influence back to Professor Rumbaugh and his investment into people.

\section{"Wrap it in plastic"}

In the late 1980s, Bill Hopkins and I were fellow graduate students, sharing an office with one another and with two adult male rhesus monkeys. One summer the air conditioning in the 150-square-foot building stopped working, and we appealed for relief from the heat, humidity, and smell. Professor Rumbaugh offered another potential solution, which was essentially to wrap the entire building in plastic so as to insulate ourselves from the heat. Fortunately, it was a short-lived experiment, but Dr. Hopkins 
and I have often laughed over the years about that period when Duane's solution to every problem (too hot, too cold, too leaky, etc.) seemed to be "wrap it in plastic."

Duane Rumbaugh was an "idea" man. He was never afraid to toss an idea out there and to let others criticize it. He wasn't concerned or embarrassed about the possibility of kiting a bad proposal (a lifetime of good ideas probably provided a considerable buffer against the occasional dud!), but rather contended that even a bad idea was better than no idea, because it at least provided a place to begin. He also championed and embodied the value of enthusiasm. He could recount many occasions in which his ideas won the day, not because they were clearly the best, but rather because he was willing to pursue and defend them with passion.

Reminiscing in his later years, Duane was also quick to acknowledge some bad ideas and regretted decisions. The missteps seemed easier for him to recall as he aged, but most of the ideas were excellent ones. I always admired his intelligence and creativity in solving problems, but it was his willingness to pursue those potential solutions energetically that really set him apart. When Duane was in, he was "all in." This is not to suggest that he was close-minded. To the contrary, Duane was receptive to other suggestions and frameworks and could be convinced that his ideas should be abandoned in favor of better ones; however, one had better come to the debate with evidence and energy to match Duane's!

The point is that the Transfer Index, and the Lana keyboard, and the Language Research Center, and the computerized test system, the tenets of Rational Behaviorism, and many other examples were all very good ideas; however, the insights would not have become accomplishments without Duane Rumbaugh's passionate and relentless pursuit of them. He was an innovator, and more than once reminded me: Innovation doesn't happen by itself; someone has to make it happen.

“ $A+++”$

From those early efforts as a graduate student to some of the most recent things that we wrote together, I'd send manuscript drafts or grant proposals to Duane for comment. He'd return the work with critical comments and helpful insights, but most were also accompanied by " $A+++$ " or some similar encouragement that the work, despite its flaws, had merit. I miss that. No matter how old you are or how long you've been in the field, it still feels great for a respected voice to say that your work is valued.

Duane Rumbaugh lived an "A+++" life. It was not without mistakes and regrets-whose is?-but it is a testament to what can be accomplished by a good man, gifted scholar, and hard worker who follows his passions for a lifetime. When I first met Duane Rumbaugh, he was 55 years old-the same age I was when he died. I could never have hoped to accomplish what Professor Rumbaugh achieved in his first 55 years. But I am inspired by the positive impact that he made on people, on the discipline, and on the world in the decades following his $55^{\text {th }}$ birthday. I pray that I, and all of us, will find A+++ ways to spend each of our remaining days. I am thankful for the many ways that I was blessed to know Duane.

And I still drive a truck.

David A. Washburn 